\title{
A percepção das adolescentes frente aos conflitos vivenciados na gravidez
}

The perception of adolescents in front of conflicts experienced in pregnancy

Percepción de los adolescentes sobre los conflictos vividos durante el embarazo

\begin{abstract}
RESUMO
Objetivo: Descrever os conflitos vivenciados por adolescentes grávidas. Método: Trata-se de um estudo exploratório, com abordagem qualitativa realizado com treze adolescentes que realizaram pré-natal na UBS Baixinha no município de Caxias-Ma no período de Janeiro de 2018 a Agosto de 2019. A produção dos dados foi realizada por meio de entrevista semiestruturada e analisada pela Classificação Hierárquica Descendente, após processamento no software IRaMuTeQ. Resultados: Foram apresentados em dois segmentos: o primeiro segmento subdividiu-se dando origem as classes 5, 4, 3, 2 e 7 ligadas aos conflitos vivenciados durante a gestação e a segunda ramificação originou as classes 1 e 6 , relacionadas aos planos de vida. Conclusão: A gravidez é um período que as adolescentes precisam de apoio da família e de toda a sociedade, pois o processo da maternidade contribui para as adolescentes abandonarem os estudos e postergar os planos de vida.
\end{abstract}

DESCRITORES: Gravidez; Adolescência; Gravidez na adolescência.

\section{ABSTRACT}

Objective: To describe the conflicts experienced by pregnant adolescents. Method: This is an exploratory study, with a qualitative approach conducted with thirteen adolescents who underwent prenatal care at UBS Baixinha in the municipality of Caxias-Ma from January 2018 to August 2019. The production of the data was carried out through semi-structured interviews and analyzed by the Descending Hierarchical Classification, after processing in the IRaMuTeQ software. Results: They were presented in two segments: the first segment was subdivided giving rise to classes 5, 4, 3, 2 and 7 linked to conflicts experienced during pregnancy and the second branch originated classes 1 and 6, related to life plans. Conclusion: Pregnancy is a period that adolescents need support from their families and society as a whole, as the motherhood process contributes to adolescents abandoning their studies and postponing their life plans.

DESCRIPTORS: Pregnancy; Adolescent; Pregnancy in Adolescence.

\section{RESUMEN}

Objetivo: Describir los conflictos vividos por adolescentes embarazadas. Método: Se trata de un estudio exploratorio, con abordaje cualitativo realizado con trece adolescentes que se sometieron a atención prenatal en la UBS Baixinha en el municipio de Caxias-Ma desde enero de 2018 a agosto de 2019. La producción de los datos se realizó mediante entrevistas semiestructuradas y analizadas por la Clasificación Jerárquica Descendente, luego de procesadas en el software IRaMuTeQ. Resultados: Se presentaron en dos segmentos: el primer segmento se subdividió dando lugar a las clases 5, 4, 3, 2 y 7 vinculadas a los conflictos vividos durante el embarazo y la segunda rama originó las clases 1 y 6 , relacionadas con los planes de vida. Conclusión: El embarazo es un período que las adolescentes necesitan del apoyo de sus familias y de la sociedad en su conjunto, ya que el proceso de maternidad contribuye a que las adolescentes abandonen sus estudios y pospongan sus planes de vida.

DESCRIPTORES: Embarazo; Adolescente; Embarazo en Adolescencia.

RECEBIDO EM: 10/04/2021 APROVADO EM: 04/05/2021

\section{Kameny Santos Franco}

Enfermeira. Graduada pelo Centro Universitário Santo Agostinho (UNIFSA). Residente em Saúde da Família pela Universidade Estadual do Maranhão (UEMA).

ORCID: 0000-0001-6056-3663 


\section{Pammela Weryka da Silva Santos}

Fisioterapeuta. Graduada pela Universidade Federal do Piauí (UFPI). Residente em Saúde da Família pela Universidade Estadual do Maranhão (UEMA). Pós-graduada em Traumato-Ortopedia e Esportiva com Ênfase em Terapia Manual pela Faculdade Einstein (FACEI).

ORCID: 0000-0002-9931-0951

\section{Marisa Araújo Costa}

Enfermeira. Graduada pela Universidade Estadual do Maranhão (UEMA). Docente do Programa de Residência em Saúde da Família da Universidade Estadual do Maranhão (UEMA). Especialista em Saúde da Família pela Universidade Federal do Maranhão (UFMA). Mestranda em Saúde da Família pela Rede Nordeste em Saúde da Família RENASF - UFMA.

ORCID: 0000-0003-3711-6042

\section{INTRODUÇÃO}

$\mathbf{N}$ o Brasil utilizam-se como parâmetro para considerar adolescentes indivíduos entre 10 e 19 anos de idade, segundo a classificação da Organização Mundial da Saúde (OMS), é o estágio do desenvolvimento humano caracterizado pela passagem para a vida adulta. Durante esse período ocorrem mudanças importantes no desenvolvimento físico, emocional e psicológico, dessa forma, é considerado um período de vulnerabilidade, associado a comportamentos de risco, como abuso de drogas e práticas sexuais desprotegidas, o que traz risco de infecções sexualmente transmissíveis e gravidezes não planejadas(1-2).

Apesar dos números de grávidas adolescentes no Brasil terem diminuído nos últimos anos, eles continuam sendo preocupantes. Após análise de relatório preliminar de dados do DATASUS-SINASC (Sistema de Informações sobre Nascidos Vivos) 2015, o número de grávidas adolescentes no país era de 18,1\% em todo o país. No ano de 2019 essa taxa caiu para $14,7 \%$, sendo que destes, 14,1\% estavam na faixa etária entre 15 e 19 anos de idade. No Brasil, a cada mil adolescentes, 53 engravidam de forma precoce, segundo o último relatório sobre a situação da população mundial, divulgado pelo Fundo de População da ONU no ano de 2020. Este índice apresentou uma discreta melhora em relação ao relatório do ano anterior, de 2019 , quando a taxa era de 62 a cada mil. Ainda assim, a média brasileira está acima do índice mundial, de 41 a cada mil $(3,6)$.

Quanto à distribuição demográfica, as regiões Nordeste e Sudeste do Brasil possuem taxas de gravidez na adolescência superiores as demais regióes nacionais. A região com maior número de mães adolescentes é a região Nordeste, com 180 mil nascidos ou $32 \%$ do total, seguido da região Sudeste, com 179,2 mil (32\%), a região Norte com 81,4 mil (14\%), a região Sul $(62.475-11 \%)$ e a Centro Oeste (43.342 - 8\%).(7)

No estado do Maranhão o quantitativo de nascidos vivos filhos de adolescentes no ano 2019 foi de 25.744 mil nascidos ou $17,9 \%$ da média regional, sendo que destes, $16,9 \%$ estavam entre 15 e 19 anos de vida. No município de Caxias-Ma foram registrados 31 nascidos vivos de adolescentes de 10 a 14 anos e entre 15 e 19 anos foram 565 , o que representa $2,2 \%$ do total de gravidez, nessa faixa etária, no estado do Maranhão (5).

A gravidez precoce entre adolescentes tem graves consequências para a saúde das mães adolescentes e de seus recém-nascidos. Complicações na gravidez e no parto são a principal causa de morte entre meninas de 15 a 19 anos em todo o mundo. Gestantes com idade entre 10 e 19 anos enfrentam maiores riscos de eclampsia, endometrite puerperal e infecções sistêmicas do que mulheres com idade entre 20 a 24 anos. Além disso, cerca de 3,9 milhões de abortos inseguros entre meninas de 15 a 19 anos ocorrem a cada ano, contribuindo para a mortalidade materna, morbidade e problemas de saúde duradouros(1).

Além das vulnerabilidades e das complicações obstétricas e perinatais, é importante ressaltar que a evasão escolar é muito mais prevalente entre adolescentes que engravidam quando comparadas com aquelas que não. Em todo o mundo a gravidez nessa fase do desenvolvimento tem maior probabilidade de ocorrer em comunidades mais carentes, comumente motivadas pela pobreza e falta de educação e oportunidades de emprego. Assim, a gravidez na adolescência, mesmo quando desejada, acarretam consequências permanentes para a sociedade e afetam o desenvolvimento humano de suas comunidades(1-2) .

A gravidez na adolescência pode se sobrepor à crise da adolescência, pois exige todo um mecanismo para reestruturar a sua identidade ao abandonar o papel e os padrões infantis. A gravidez ocorrendo nessa fase da vida aciona uma nova busca para redefinição de papéis, com novos conflitos capazes de acarretar uma maior desestruturação da personalidade, articulada com mudanças orgânicas e psíquicas ${ }^{(8)}$.

Desta forma, o estudo justifica-se na importância de uma gravidez durante o adolescer, por representar uma questão de fundo psicossocial, pois reúne conflitos emocionais, psíquicos, sexuais, sociais e culturais. Reações como medo, insegurança, desespero, desorientação, solidão são muito comuns, principalmente no momento da descoberta da gestação (9).

O estudo buscou resposta a seguinte questão: "Qual a percepção das adolescentes frente aos conflitos vivenciados na gravidez?" O objetivo por conseguinte foi descrever os conflitos vivenciados pelas adolescentes grávidas.

\section{MÉTODO}

Trata-se de um estudo exploratório, com abordagem qualitativa efetuado com treze adolescentes que realizaram pré-natal na UBS Baixinha no município de Caxias -Ma, no período de Janeiro de 2018 a Agosto de 2019. Gestantes que tiverem menos de três (03) consultas de pré-natal foram excluídas 
do estudo, pois considera-se que a adolescente não criou um vínculo de confiança com a equipe. A principal fonte de coleta de dados foi uma entrevista semiestruturada conforme objetivos a serem alcançados. As entrevistas foram gravadas em áudio, e, posteriormente, transcritas, integralmente, uma a uma.

Quando na residência das adolescentes, mediante agendamento do dia e horário, era solicitado para assinarem o Termo de Assentimento Livre e Esclarecido (TALE), o mesmo era acessível e adaptado ao nível de compreensão das mesmas, contando com informações sobre a pesquisa e seus objetivos para que tivessem conhecimento do que estariam participando, além de enfatizar a liberdade de deixarem de participar quando quiserem, permitindo às mesmas escolherem participar ou não da pesquisa e assinarem o documento confirmando sua escolha. O Termo de Consentimento Livre e Esclarecido (TCLE) foi pedido para o responsável das colaboradoras da pesquisa assinarem autorizando a entrevista. O TALE e o TCLE foram em duas vias, mantendo uma no poder da colaboradora e responsável respectivamente e a outra com a pesquisadora. Posteriormente, era realizado individualmente, em um ambiente da residência que a adolescente se sentia confortável e mantendo a privacidade da mesma, uma entrevista semiestruturada com perguntas que responderam aos objetivos da pesquisa. As entrevistas duraram em média 15 a 20 minutos.
Para analisar os conteúdos textuais foram utilizadas as técnicas de classificação hierárquica descendente, análise de similitude e nuvem de palavras, na qual organizam graficamente de acordo com sua frequência. Estas técnicas de análise permitiram facilmente sua identificação por meio de um arquivo único, devidamente configurado em formato texto e denominado Rapport ou corpus e segmentos de texto, que correspondem aos textos originais da entrevista. Após a transcrição e leitura do material arquivado, foi construído um modelo analítico composto por categorias, que corresponderão às classes de palavras geradas pelo software IRAMUTEQ.

A análise interpretativa do corpus foi pelo uso da Análise de Conteúdo de Bardin, esta consiste em uma técnica metodológica que se pode aplicar em discursos diversos e a todas as formas de comunicação, seja qual for à natureza do seu suporte. $\mathrm{Na}$ abordagem quantitativa se traça uma frequência das características (palavras) que se repetem no conteúdo do texto e na qualitativa, se considera o conjunto de características em um determinado fragmento do conteúdo, e este foi possível com o uso do software IRAMUTEQ (10-11).

Os preceitos éticos foram seguidos conforme determina a legislação, sendo o projeto de pesquisa submetido ao Comitê de Ética em Pesquisa da Universidade Es- tadual do Maranhão (UEMA) e aprovado sob número de parecer 3.692.374 e CAAE: 22340919.0 .0000 .5554 .

\section{RESULTADOS}

Após o processamento dos depoimentos, o software reconheceu o corpus em oitenta e seis Unidades de Contexto Elementar (UCE) a partir de treze Unidades de Contexto Inicial (UCI), com ocorrência de 3.028 palavras e aproveitamento de $88,37 \%$. O corpus sofreu divisões e subdivisões que deram origem a dois segmentos. O primeiro segmento subdividiu-se dando origem as classes 5, 4, 3, 2 e 7 ligadas aos conflitos vivenciados durante a gestação e a segunda ramificação originou as classes 1 e 6 , relacionadas aos planos de vida. $\mathrm{Na}$ figura 1 encontra-se o Dendograma com a distribuição espacial das classes e as palavras mais relevantes.

A partir do dendograma iniciou-se a análise das sete classes fornecidas pelo software IRAMUTEQ, na qual as UCE agrupadas em cada classe foram lidas exaustivamente para compreender e nominar cada classe a seguir.

\section{Classe 5 - Preconceito na condição da maternidade}

Diante do depoimento das adolescentes é possível identificar o preconceito sofrido por elas. Referem que a pouca idade

\section{Figura I: Dendograma das classes obtidas a partir do corpus. Caxias-MA, Brasil, 2020.}

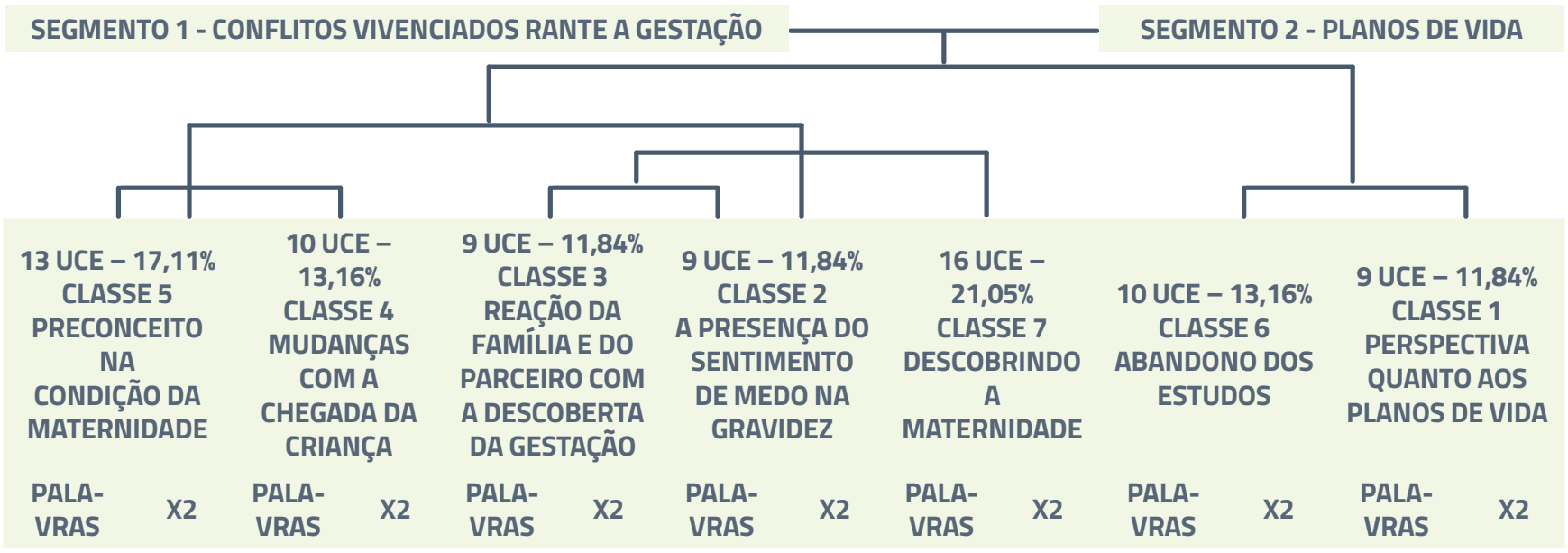




\begin{tabular}{|c|c|c|c|c|c|c|c|c|c|c|c|c|c|}
\hline Dizer & 30.05 & Tio & 20.93 & $\begin{array}{l}\text { Plane- } \\
\text { jar }\end{array}$ & 39.84 & Pegar & 31.43 & Porque & 15.66 & Estudar & 22.11 & $\begin{array}{c}\text { Engravi- } \\
\text { dar }\end{array}$ & 33.05 \\
\hline Familia & 8.72 & Morrer & 20.93 & Feliz & 17.69 & Medo & 21.71 & Já & 13.45 & Muito & 12.44 & $\begin{array}{l}\text { Aconse- } \\
\text { Ihar }\end{array}$ & 31.43 \\
\hline Querer & 7.29 & Tudo & 13.05 & $\begin{array}{l}\text { Gesta- } \\
\text { ção }\end{array}$ & 16.06 & Passar & 10.39 & $\begin{array}{l}\text { Desco- } \\
\text { brir }\end{array}$ & 12.78 & Bom & 8.75 & Hoje & 18.69 \\
\hline Deixar & 5.41 & Morar & 10.62 & Mãe & 6.41 & Mandar & 8.99 & Alegre & 11.71 & Menina & 7.83 & Plano & 17.69 \\
\hline Mulher & 5.41 & Aí & 10.14 & Normal & 5.89 & Dia & 8.99 & Mês & 9.24 & Quando & 4.3 & Nada & 11.89 \\
\hline Triste & 5.41 & Menos & 7.83 & Chorar & 5.89 & Hora & 8.99 & Gostar & 8.15 & Escola & 3.37 & $\begin{array}{c}\text { Faculda- } \\
\text { de }\end{array}$ & 9.09 \\
\hline Homem & 5.41 & Como & 7.83 & Pai & 5.27 & Barriga & 8.99 & Falar & 7.18 & $\begin{array}{l}\text { Conti- } \\
\text { nuar }\end{array}$ & 3.37 & Melhor & 8.99 \\
\hline Filho & 5.11 & Pai & 7.18 & Ficar & 4.14 & Só & 7.41 & Mãe & 6.49 & Vez & 3.37 & Difícil & 8.99 \\
\hline Terminar & 4.97 & Querer & 6.06 & Gente & 4.06 & Depois & 4.6 & Novo & 6.04 & $\begin{array}{c}\text { Faculda- } \\
\text { de }\end{array}$ & 2.32 & Gravidez & 7.31 \\
\hline Ainda & 4.97 & Nascer & 5.02 & Bem & 4.06 & Vida & 4.06 & $\begin{array}{l}\text { Quan- } \\
\text { do }\end{array}$ & 5.71 & Mim & 10.28 & Filho & 6.48 \\
\hline Neném & 2.69 & Casa & 3.64 & Neném & 3.98 & $\begin{array}{l}\text { Mo- } \\
\text { mento }\end{array}$ & 4.06 & Ficar & 4.2 & Sem & 3.37 & Bem & 4.06 \\
\hline Morar & 2.62 & Depois & 3.57 & Medo & 3.93 & $\begin{array}{l}\text { Gesta- } \\
\text { ção }\end{array}$ & 4.06 & Ficar & 3.91 & Pessoa & 2.86 & $\begin{array}{l}\text { Conti- } \\
\text { nuar }\end{array}$ & 4.06 \\
\hline Coisa & 2.62 & Nada & 3.37 & Só & 3.93 & $\begin{array}{l}\text { Come- } \\
\text { çar }\end{array}$ & 3.64 & Logo & 3.91 & Fazer & 2.49 & Estudar & 3.64 \\
\hline \multirow[t]{13}{*}{ A } & 4.59 & $\begin{array}{l}\text { Sozi- } \\
\text { nho }\end{array}$ & 2.32 & Início & 2.88 & Pensar & 2.88 & Reação & 3.91 & & & Não & 3.44 \\
\hline & & Outro & 7.26 & Pensar & 2.36 & Aceitar & 2.36 & $\begin{array}{l}\text { Mens- } \\
\text { truação }\end{array}$ & 3.91 & & & Mais & 2.88 \\
\hline & & Meu & 3.84 & Familia & 2.07 & Em & 2.07 & Saber & 3.36 & & & Sentir & 2.88 \\
\hline & & Todo & 3.64 & Novo & 2.07 & Nenhum & 14.04 & $\begin{array}{l}\text { Tam- } \\
\text { bém }\end{array}$ & 3.36 & & & Trabalhar & 9.09 \\
\hline & & Por & 2.48 & 0 & 4.02 & Ir & 7.1 & Depois & 2.22 & & & Este & 8.99 \\
\hline & & Minha & 2.37 & Minha & 3.79 & Com & 5.31 & Vir & 2.13 & & & Ter & 5.31 \\
\hline & & & & Por & 3.51 & Primeiro & 4.06 & Sair & 2.13 & & & & \\
\hline & & & & & & Eu & 2.72 & Três & 7.39 & & & & \\
\hline & & & & & & Ter & 2.42 & Estar & 7.21 & & & & \\
\hline & & & & & & Tempo & 2.07 & Tempo & 6.04 & & & & \\
\hline & & & & & & & & Um & 4.61 & & & & \\
\hline & & & & & & & & $\begin{array}{l}\text { Nin- } \\
\text { guém }\end{array}$ & 3.91 & & & & \\
\hline & & & & & & & & Comigo & 2.21 & & & & \\
\hline
\end{tabular}

reflete uma imaturidade para cuidar do filho, além de serem aconselhadas a abandonarem a criança ou dá para uma terceira pessoa cuidar.

\section{[...] as pessoas brigavam, diziam que} eu era muito nova para ter filho $e$ quando eu tivesse a neném era para eu abandonar na porta de uma casa (AS).

Ela (mãe) estava triste e queria dá a minha filha quando nascesse. Eu ficava com medo. (A6)
Classe 4 - Mudanças com a chegada da criança

O nascimento do bebê apresentou-se como momento de mudanças com impactos positivos tanto para a adolescente quanto para seus familiares, dentre eles, as adolescentes mencionaram: alegria para o 
lar, acolhimento por parte de colegas da escola e família.

Meu pai agora depois que a neném nasceu é apaixonado por ela (A12). [...] depois que eu tive o neném foi tudo diferente, todo mundo na escola começou a falar comigo. Era mimo para cá e para lá (A8).

\section{Classe 3 - Reação da família e do parceiro} com a descoberta da gestação

De acordo com o relatado pelas adolescentes, os parceiros diante da notícia da gravidez, revelaram o desejo de ser pai tendo a gravidez sido planejada ou não.

Minha gestação não foi planejada, mas o pai do neném ficou feliz (A2). [...] o pai do neném ficou feliz (A7).

Porém para a família foi difícil no primeiro momento aceitar, sendo a mãe, a integrante da família que mais desaprovou a gravidez das filhas, seguida do pai.

Minha mãe ficou muito brava, porque eu fiquei grávida nova. Mas agora está tudo normal (A1).

Minha mãe de início ela surtou, mas depois ficou bem (A4).

Porém uma adolescente referiu que os seus pais ficaram contentes com a notícia da gestação.

Minha mãe ficou bestinha, pois seria avó, $e$ o avô piorou só fica mandando presente e dinheiro (A3).

\section{Classe 2 - A presença do sentimento de medo na Gravidez}

As adolescentes referem o sentimento de medo em algum momento da gestação, seja ele durante o trabalho de parto, por problemas conjugais, descoberta e experiência da maternidade. Além do medo de morrer por conta de uma gestação com complicaçôes.

Eu tive medo só na hora do parto, fiquei muito nervosa (A13).

[...] no começo eu fiquei com medo, mãe de primeira viagem, né? (A11). [...] ele (parceiro) infernizou minha vida. Tive medo, raiva, eu sofri demais (AS).

\section{Classe 7 - Descobrindo a maternidade}

As adolescentes referem sentimentos de pânico, decepção, surpresa, medo e alegria ao descobrirem a gestação mesmo tendo planejado.

[...] quando eu descobri fiquei feliz demais, nunca imaginei (A1).

Minha reação foi de pânico. Fiquei com medo da minha mãe descobrir e bater, brigar comigo. (A3)

Fiquei decepcionada por estar decepcionando-a (responsável da adolescente). (A5)

Eu chorei muito e fiquei pensando que teria que largar a escola (A12).

\section{Classe 6 - Abandono dos estudos}

Algumas adolescentes abandonaram os estudos por conta da gravidez e nascimento do filho e relataram uma tristeza quanto isso, mas expressam o desejo de retomar para concluírem o ensino médio e/ou ingressarem no ensino superior.

2uando eu vejo as pessoas que estudavam comigo ter terminado os estudos, as vezes eu fico triste, mas eu tenho fé, nunca é tarde para terminar os estudos da gente. (A8)

[...] mas futuramente pretendo estudar (A10).

Classe 1 - Perspectiva quanto aos planos de vida

As adolescentes confessam que os planos que tinham para a sua vida foram adiados, mas que continuam os mesmos, porém com prioridades diferentes, oferecer um futuro melhor para os filhos.

Os planos que eu tinha antes de engravidar continuam os mesmos. Planos de terminar os estudos, fazer uma faculdade e agora eu tenho mais um motivo, a gravidez, é muita responsabilidade (A10).
Diferente da maioria, uma adolescente afirma que seus planos de vida mudaram depois da gestação, porém não os tem definidos.

Hoje meus planos mudaram, mas ainda não sei dizer quais são. Eu não aconselho engravidar, ter filhos na adolescência (A9).

\section{DISCUSSÃO}

A descoberta da gravidez na adolescência traz à tona vários sentimentos, como o medo de dizer para a família, o receio da decepção dos pais, desespero, dúvida, incerteza diante da situação da maternidade e o preconceito. A existência de preconceitos ocorre tanto por parte da família quanto pela sociedade. As adolescentes sentem-se intimidadas para abordar as questões que envolvem sexualidade devido aos sentimentos de repreensão impostos e quando engravidam esses sentimentos tendem a aflorar, intensificando os julgamentos e preconceitos(12).

O envolvimento da família ocorre de forma positiva após o nascimento do bebê. Percebe-se uma maior aproximação da família e do companheiro dessas adolescentes, passando também a demonstrar maior cuidado e proteção. As mães das adolescentes descrevem sentimentos, como felicidade, alegria e apoio no relacionamento com as filhas por meio de diálogo e acompanhando as adolescentes durante a nova fase. A figura materna surge como eixo para a continuação dos projetos de vida, bem como o fortalecimento dos vínculos familiares. Embora aceitem a gravidez, demonstraram não ter gostado da notícia ao recebê-la, assim como o pai, sendo difícil lidar com tal situação $(13,15)$.

Quanto a reação dos cônjuges, apesar de ficarem chocados com a notícia da paternidade durante a adolescência, conseguem iniciar o processo de ser pai, exercendo papeis, habilidades e conhecimentos até então não desenvolvidos por eles. As reações dos parceiros diante da gravidez da adolescente variam desde a aceitação imediata até reações negativas, incluindo desde dúvidas e 


\section{artigo}

Franco, K.S.; Santos, P.W.S.; Costa, M.A.;

A percepção das adolescentes frente aos conflitos vivenciados na gravidez

questionamentos quanto à real paternidade da criança até a sugestão do aborto(13-14).

Ao descobrirem a gestação, as adolescentes apresentam sentimentos de insegurança, medo, rejeição, por não se sentirem preparadas para exercer a função de mãe. A primeira reação é descrita como um susto, tanto para elas quanto para a família, ocasionado pelo não planejamento da gestação e possível negação da condição de gestar um filho. Diante desses sentimentos vivenciados, a rede de apoio familiar e do companheiro têm como principal função elevar a autoestima e evitar maiores traumas psicológicos decorrentes das transformações oriundas de uma gestação na adolescência $(12,14)$.

A maternidade reduz a frequência das mulheres à escola. Vivências anteriores, como ter presenciado julgamentos de outras adolescentes grávidas, faz com que elas se ausentem da escola para evitar constrangimentos. Além de entender que a dedica- ção ao filho é prioridade e que os estudos poderão ser retomados no futuro. Nesta direção, a gestação precoce pode trazer desvantagens à trajetória educacional da adolescente, contribuindo para a evasão escolar e dificultando o retorno à escola. Assim, a gravidez na adolescência está associada com altos índices de evasão escolar. Contudo, planejam retornar à escola para aumentar a possibilidade de oferecer oportunidades ao futuro dos filhos $(9,12)$.

A falta de perspectiva para o futuro em algumas jovens, indica que a adolescente não se encontra preparada para lidar com a realidade de ter que assumir responsabilidades que implicam em ter um filho, como o sustento e cuidado que uma criança precisa. Dessa forma os planos de seguir com uma profissão são incertos, visto que agora é preciso cuidar do bebê. $O$ fato de ter um filho traz consigo o significado de mudança na rotina e, também, no planejamento de vida das adolescentes(12).

\section{CONCLUSÃO}

As adolescentes sofrem preconceitos durante a gravidez, as mesmas são vistas pelos familiares e sociedade como incapazes de cuidar de uma criança. Diante da notícia da descoberta da gestação, revelam a difícil aceitação por parte dos familiares e referem sentimentos de decepção, surpresa, medo e alegria. No que diz respeito aos estudos e os planos de vida, ficaram em segundo plano.

Diante disso, a gravidez é um período que as adolescentes precisam de apoio da família e de toda a sociedade, pois o processo de engravidar contribui para o abandono dos estudos e postergar os planos de vida, contribuindo para que haja uma baixa qualidade de vida futura e perda de oportunidades profissionais para essas jovens. Logo, a gravidez na adolescência pode estar ligada a sentimentos negativos sendo entendida como algo que ameaça o futuro e gera conflitos. -

\section{REFERÊNCIAS}

1. Buratto J, Kretzer MR, Freias PF, Traebert J, Nunes RD. Temporal trend of adolescent pregnancy in Brasil. Rev. Assoc. Med. Bras. 2019; 65(6): 880-885.

2. OMS. Gravidez na Adolescência [Internet]. 2021 [acesso 2021 Mar 01]. Disponível em: https://www.who. int/en/news-room/ fact-sheets/detail/adolescent-pregnancy.

3. Campos FJSS, Silva ABP, Silva DFA, Pinto DS, Cunha KC. Análise dos casos de gravidez na adolescência no estado do Pará, Brasil. Adolesc Saude. 2020;17(3):96-104.

4. Rosaneli CF, Costa NB, Sutile VM. Proteção à vida e à saúde da gravidez na adolescência sob o olhar da Bioética. Physis. 2020; 30(1): e300114.

5. Brasil, Ministério da Saúde. Banco de dados do Sistema Único de Saúde-DATASUS. Disponivel em: http://tabnet.datasus.gov. br/cgi/deftohtm.exe?sinasc/cnv/nvma.def. Acesso: 01 março 2021.

6. UNFPA. Investimento em serviços de saúde reprodutiva, informação e empoderamento de meninas é fundamental para prevenir gravidez precoce [Internet]. 2021 [acesso 2021 Maio 01]. Disponivel em: https://brazil.unfpa.org/pt-br/news/investimento-em-servi\%C3\%A7os-de-sa\%C3\%BAde-reprodutiva-informa\%C3\%A7\%C3\%A30-e-empoderamento-de-meninas-\%C3\%A9.

7. Jesus BMH, Bezerra LD, de Sousa SM, Castro CMD, Alves RM, Soares NT. Gravidez na adolescência e a assistência de enfermagem: uma abordagem sobre os riscos à saúde maternal e neonatal. SaudColetiv (Barueri). 2021; 11(61):4978-89.
8. Silva, GV; Abrao, JLF da. Experiências emocionais da gravidez na adolescência: entre expectativas e conflitos. Bol. - Acad. Paul. Psicol., São Paulo, 2020; 40(98):63-72.

9. Rodrigues MP, Nascimento CMBV do, Melo RHV de, Oliveira DA de, Ferreira M, Ângela F, Oliveira AP de. Percepções sobre os efeitos psicossociais da gravidez na adolescência no cenário da estratégia saúde da família. rev. ciênc. Plural. 2017;3(1):81-7.

10. Urquiza MA, Marques DB. Análise de conteúdo em termos de Bardin aplicada à comunicação corporativa sob o signo de uma abordagem teórico-empírica. Entre textos. 2016; 16(1):115-144.

11. Moimaz SAS, Amaral MA, Miotto AMM, Costa ICC, Garbin CAS. Análise qualitativa do aleitamento materno com o uso do software IRAMUTEQ. Saúde e Pesquisa 2016;9(3):567-77.

12. Costa GF, Siqueira DD, Rocha FAA, CFBC, Branco JGO. Fatores psicossociais enfrentados por grávidas na fase final da adolescência. Fortaleza, Rev Bras Promoç Saúde, 2018, 31(2): 1-8.

13. Cremonese L, Wilhelm LA, Demori CC, Prates LA, Barreto CN, Ressel LB. Vivências do Período Gravídico-Puerperal na Perspectiva de Mulheres Adolescentes. Rev Fund Care Online. 2019; 5(11):1148-1154.

14. Corrêa ACL, Meincke SMK, Schwartz E, Oliveira AMN de, Soares MC, Jardim VMR. Percepções de homens sobre a vivência da paternidade na adolescência: uma perspectiva bioecológica. Rev. Gaúcha Enferm. 2016; 37(1): e54692.

15. Nunes G, Leite K, Lima T, Paulo A, Souza T, Nascimento B, Neves R, Medeiros F. Sentimentos vivenciados por primigestas. Revista de Enfermagem UFPE. 2018 Abr 4; 12(4): 916-922. 